\title{
ACE Inhibitor Related Angioedema: A Case Report and Brief Review
}

\author{
F. Brian Boudi, J. L. Rush, Cameron Farsar, Connie S. Chan \\ Carl T. Hayden VA Medical Center \\ University of Arizona, College of Medicine Phoenix Campus \\ Phoenix, AZ USA
}

\begin{abstract}
We present a case report of angiotensin converting enzyme (ACE) inhibitor angioedema successfully treated with icatibant (Firazyr $\left.{ }^{\circledR}\right)$. The pathophysiology and treatment of ACE inhibitor angioedema is reviewed.

\section{Introduction}

Angioedema, swelling caused by a rapid increase in permeability of submucosal or subcutaneous capillaries and post-capillary venules with localized plasma extravasation, is associated with random, highly variable and often unpredictable clinical manifestations (1). Attacks are associated with significant decreased quality of life both during and between attacks, significant functional impairment and a high risk of morbidity and mortality. Angioedema can be caused by either mast cell degranulation or activation of the kallikrein-kinin cascade. ACE inhibitor-related angioedema is one the leading causes of drug-induced angioedema. While ACE inhibitor-induced angioedema is rare, awareness of this serious and potentially life-threatening complication is of great importance because of the extensive use of this class of drugs in clinical practice. Cases presenting into the emergency department because ACE inhibitors, one of the most widely prescribed medications prescribed in the United States, account for about 20-40 percent of emergency room admissions related to angioedema $(1,2)$.

Approximately $50 \%$ of patients with ACE inhibitor-induced angioedema arise within the first week of treatment. The remainder can become symptomatic weeks, months, or even years later. The estimated incidence is likely underestimated. The actual incidence can be far higher because of poorly recognized presentation of angioedema and its sometimes-late onset. The incidence can be even higher (up to 3-fold) in certain risk groups, for instance Afro-Americans (3). It seems to have a predilection for the head, neck, lips, mouth, tongue, larynx, pharynx, and subglottal areas without urticaria (4).
\end{abstract}

\section{Case Presentation}

A 55-year-old veteran presented to the Emergency Department for the Carl T. Hayden Veterans Administration Medical Center in Phoenix Arizona with impressive angioedema. The Veteran had been taking lisinopril for 6 years and had another similar episode two months prior. The prior episode presented with 
facial swelling that resolved within a couple of hours. However, the present episode was accompanied by difficulty breathing and swallowing. He was begun on an allergic reaction protocol which included establishing and making sure the veteran had a patent airway, nasal trumpet, placing a peripheral intravenous catheter and starting iv fluid of sodium chloride $0.9 \%$ to keep vein open, medications of diphenhydramine $50 \mathrm{mg}$, famotidine $20 \mathrm{mg}$, methylprednisolone $125 \mathrm{mg}$ and $0.3 \mathrm{mg}$ epinephrine subcutaneously. He was also given racemic epinephrine mixed via nebulizer and $30 \mathrm{mg}$ subcutaneously of icatibant (Firazyr $\left.{ }^{\circledR}\right)$, a bradykinin B2 receptor antagonist used to treat hereditary angioedema. He improved and was subsequently admitted to the intensive care unit for continued observation. The following day he was discharged with prescriptions for prednisone and orders to discontinue the use of lisinopril.

\section{Discussion}

Despite newer therapies, there are no currently approved guidelines for the treatment of ACE inhibitor-induced angioedema in the United States. It is difficult to tell whether icatibant was truly effective in this case presentation as it was one of multiple therapies administered. Many causes of angioedema result from release of histamine (1). However, ACE inhibitor angioedema results from other inflammatory mediators, especially bradykinin (2) (Figure 1).

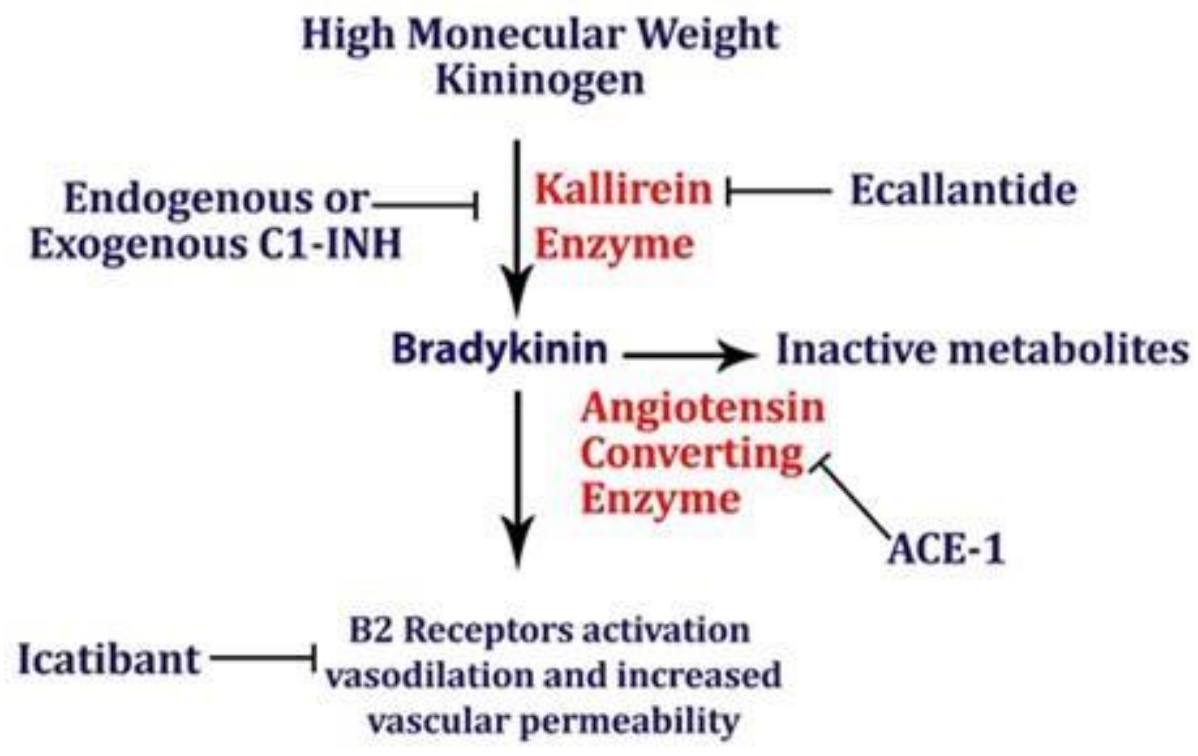

Figure 1. Simplified pathway for bradykinin-mediated angioedema showing the sites of drug activity (5).

Mast cells are not believed to be involved in this form of angioedema, and pruritus and urticaria are absent. Bradykinin-mediated angioedema, unlike histamine-mediated angioedema, frequently affects the gastrointestinal mucosa, leading to bowel wall edema and presenting with episodes of abdominal pain, nausea, vomiting, and/or diarrhea. While antihistamines and corticosteroids are 
often administered for treatment of angioedema, they are unlikely to have effect in ACE inhibitor induced angioedema. Epinephrine may slow (or stop) the rate of swelling. ACE inhibitor angioedema may be treated with additional drugs that act on the bradykinin pathway (e.g., icatibant, ecallantide). The recommended dose of icatibant is $30 \mathrm{mg}$ administered by subcutaneous (SC) injection in the abdominal area. Additional doses may be administered in 6 hours if response is inadequate. Icatibant may decrease the time of recovery from ACE inhibitor related angioedema (6). Another ACE inhibitor should not be prescribed as the reaction is a class, not a drug specific reaction (7). Checking the complement $\mathrm{C} 4$ may be helpful. Patients with preexisting angioedema, including hereditary angioedema caused by $\mathrm{C} 1$ esterase inhibitor deficiency, are predisposed to develop angioedema in response to ACE inhibitors (8).

ACE inhibitor induced angioedema remains a disorder without a clear treatment modality for reduction of symptoms. The primary therapeutic interventions remain removal of the offending agent and airway management when indicated. The use of icatibant may be effective in the management of ACE inhibitor related angioedema; however, its efficacy and benefits have not been clear in the small studies published thus far. There have been three randomized trials evaluating the use of icatibant in ACE inhibitor angioedema. Interestingly, the first study found icatibant to be effective while the more recent and larger studies found no significant difference in time to recovery $(3,6,9-12)$. Icatibant is costly with a wholesale price of $\$ 9,000-\$ 11,000$ and may not be available at all hospitals. Given its questionable outcomes data, icatibant may not appropriate in all medical centers. This is especially important since off-label use may not be covered by insurers.

\section{References}

1. Stone C Jr, Brown NJ. Angiotensin-converting enzyme inhibitor and other drug-associated angioedema. Immunol Allergy Clin North Am. 2017 Aug;37(3):483-495. [CrossRef] [PubMed]

2. Guyer AC, Banerji A. ACE inhibitor-induced angioedema. UpToDate. June 27, 2017. Available at: https://www.uptodate.com/contents/an-overview-ofangioedema-clinical-features-diagnosis-and-management\#H30 (requires subscription, accessed 9/18/17).

3. Straka BT, Ramirez CE, Byrd JB, et al. Effect of bradykinin receptor antagonism on ACE inhibitor-associated angioedema. J Allergy Clin Immunol. 2017;140:242-248.e2. [CrossRef] [PubMed]

4. Sabroe R, Black A. Angiotensin-converting enzyme (ACE) inhibitors and angio-oedema. Br J Dermatol. 1997;1:153-8. [CrossRef] [PubMed]

5. Shenvi C, Serrano K. New treatments for angioedema. Emergency Physicians Monthly. 9/12/16. Available at: http://epmonthly.com/article/newtreatments-angioedema/ (accessed 10/20/17). 
6. Baş M, Greve J, Stelter K, et al. A randomized trial of icatibant in ACEinhibitor-induced angioedema. N Engl J Med. 2015 Jan 29;372(5):418-25. [CrossRef] [PubMed]

7. Johnsen SP, Jacobsen J, Monster TB, Friis S, McLaughlin JK, Sørensen HT.Risk of first-time hospitalization for angioedema among users of ACE inhibitors and angiotensin receptor antagonists. Am J Med. 2005;1:1428-9. [CrossRef] [PubMed]

8. Orfan N, Patterson R, Dykewicz M. Severe angioedema related to ACE inhibitors in patients with a history of idiopathic angioedema. JAMA. 1990;1:1287-9. [CrossRef] [PubMed]

9. Sinert R, Levy P, Bernstein JA, et al.Randomized trial of icatibant for angiotensin-converting enzyme inhibitor-induced upper airway angioedema. $J$ Allergy Clin Immunol Pract. 2017 Sep-Oct;5(5):1402-9.e3. [CrossRef] [PubMed]

10. Culley CM, DiBridge JN, Wilson GL Jr. Off-label use of agents for management of serious or life-threatening angiotensin converting enzyme inhibitor-induced angioedema. Ann Pharmacother. 2016 Jan;50(1):47-59 [CrossRef] [PubMed]

11. Fok JS, Katelaris $\mathrm{CH}$, Brown AF, Smith WB. Icatibant in angiotensinconverting enzyme (ACE) inhibitor-associated angioedema. Intern Med J. 2015 Aug;45(8):821-7. [CrossRef] [PubMed]

12. Riha HM, Summers BB, Rivera JV, Van Berkel MA. Novel therapies for angiotensin-converting enzyme inhibitor-induced angioedema: a systematic review of current evidence. J Emerg Med. 2017 Sep 19. pii: S07364679(17)30489-4. [CrossRef] [PubMed] 